\title{
RUINAS Y RECUERDOS: SOBRE JUAN RULFO COMO ARQUITECTO LITERARIO
}

\author{
Martin Zerlang
}

\begin{abstract}
RESUMEN
En este artículo, se analiza la obra de Juan Rulfo como una estructura construida con base en la memoria y en los recuerdos.
\end{abstract}

\begin{abstract}
Juan Rulfo's work is analyzed in this article as a structure built on the basis of memory and recollections.
\end{abstract}

\section{Al margen de la historia}

"Quiero no hablar como se escribe, sino escribir como se hable", ha dicho Juan Rulfo (Roffé 1973: 55), y su obra tiene un carácter marcadamente oral, como escrita en voz baja, como murmullos lejanos. Su lenguaje lacónico y lapidario da un impresión de un autor invisible, casi inaudible; no obstante, Rulfo se cuenta entre los autores más notables de la literatura latinoamericana.

Es una paradoja evidente que la obra de Rulfo sobre los olvidados — con ecos lejanos de la vida y especialmente la muerte de los habitantes de Jalisco en México- haya obtenido una posición absolutamente central. Esa obra sobre conflictos de tierras y enfrentamientos de padres e hijos, sobre revoluciones e inundaciones, parece una transposición de la cultura y la "mentalidad" campesina del Jalisco (Roffé 1973: 65), donde, según Rulfo, la gente hermética "casi no habla, más bien” (Roffé: 54).

La novela Pedro Páramo y los cuentos de El llano en llamas con su prosa parca y apretada han inspirado elogios de autores como Asturias, Arguedas, Onetti, Fuentes, Poniatowska, Roa Bastos, García Márquez: todos preconizan su material temático y su estilo sutil como una revelación de las culturas mexicana y latinoamericana. Sin embargo, como una paradoja de las paradojas, Rulfo ha dicho que fueron autores de Rusia y Escandinavia los que más le impresionaban y aún "tuv[o] alguna vez la teoría de que la literatura nació en Escandinavia” (Roffé: 49). Así, menciona autores como Bjørnstjerne Bjørnson, Knut Hamsun, Selma Lagerlöf y Haldor Laxness y dice: "Me interesaban por ese ambiente un poco neblinoso. Al 
mismo tiempo me parecía un mundo muy extraño, muy lejano del nuestro, pero en donde encuentro las mismas similitudes de todos los hombres" (Antolín 1991: 14. Cf. el ensayo de Rulfo sobre la "Situación actual de la novela contemporánea", en Fell 1992: 371).

En esa atención a la vida al margen de la historia se encuentra la raíz del parentesco entre los autores nórdicos del siglo XIX y ciertos autores de Latinoamérica del siglo XX: son autores periféricos y transculturados, en el sentido en que se destaca en el libro Transculturación narrativa en América Latina, donde escribe Ángel Rama:

\footnotetext{
El escritor que para muchos inicia la escritura de vanguardia en la narrativa mexicana no se ha dirigido a las figuras centrales de la vanguardia europea que han respaldado la gran producción latinoamericana (Joyce, Woolf, Kafka, Musil), sino a los representantes de una periferia europea que medio siglo antes que los latinoamericanos, hicieron la experiencia de una modernidad que les venía de los grandes centros metropolitanos" (Klahn 1992: 425).
}

Los periféricos y los olvidados son el tema de la obra de Rulfo y, si quisiera buscar una fórmula de la obra de Juan Rulfo, esa fórmula sin duda sería "Acuérdate" (como manda o demanda el narrador en el cuento del mismo título). El olvido y la memoria son los polos del eje sobre el cual giran la novela y los cuentos de Rulfo. Puede ser que el olvido haya borrado los perfiles de este imperio de sombras, donde los personajes viven su muerte, y puede ser que algunos de esos quieran que el olvido borre sus actos malos, pero la obra como tal demuestra un esfuerzo intenso e insistente por recordar. El cuento pequeño de Acuérdate, una epopeya de cuatro páginas sobre víctimación y expulsión, termina con un llamamiento a la memoria del interlocutor callado: "Tú te debes acordar de él, pues fuimos compañeros de escuela y lo conociste como yo".

\section{El pasado de Rulfo}

En su novela Volverás a Región, Juan Benet escribe que "la memoria sólo es el registro del dolor" (Ezquerro 1987: 136). En el caso de Rulfo, el registro de familiares es un registro del dolor que se puede resumir así: "En la familia Pérez Rulfo (...) nunca hubo mucha paz; todos morían temprano... y todos eran asesinados por la espalda" (Roffé: 30). Los padres eran hacendados que perdían todo en la revolución (Fell 1992: 816), y su hacienda la quemaron cuatro veces cuando todavía vivía su padre. El padre fue matado cuando Rulfo tenía seis años; la madre murió cuando tenía ocho años; el tío fue asesinado; a su abuelo le "colgaron de los dedos gordos" y los perdió; al cura "lo colgaron en un poste del télegrafo" (Roffé: 41). Hasta los diez años Rulfo vivió en San Gabriel, "uno de esos pueblos que han perdido hasta el nombre" (Roffé: 46), y después pasó unos cinco o seis años en un orfanatorio.

Así, se entiende que es un pasado que debe haber dejado heridas en la mente de Rulfo, por lo que cuando se mudó a la ciudad, a Guadalajara y después a la Ciudad de México, la angustia y la soledad fueron acompañantes fieles:

No conocía a nadie. Convivía con la soledad, hablaba con ella, pasaba las noches con mi angustia y mi conciencia. Hallé un empleo en la oficina de Migración y me puse a escribir para librarme de aquellas sensaciones (Cuadernos Hispanoamericanos 1985: 5). 
"Yo platicaba, charlaba con la soledad", dice Rulfo (Roffé: 53), pero su obra muestra que por esas charlas, recuerdos de diferentes tiempos se superponían: la memoria de los padres - como en Pedro Páramo donde Juan Preciado ve el pueblo Comala "a través de los recuerdos de mi madre" (180); los recuerdos traumáticos de su infancia; y después de "las épocas de las revoluciones" (Roffé: 41) -especialmente la revolución cristera que caracteriza como tonta e inútil (Antolin: 16)- las observaciones del éxodo rural, la sensibilidad de los campesinos que buscan una vida nueva en la ciudad, "el shock que reciben al querer adaptarse a un medio hostil, que a veces los rechaza y a veces los absorbe" (Roffé: 77), evidentemente una sensibilidad y un shock que Rulfo conocía de sí mismo.

\section{Un palacio - o una casita - de memoria}

El tema general de la obra de Rulfo es la experiencia y los recuerdos de shocks. Una ambición restauradora impregna su novela y sus cuentos: quemaron la casa de su infancia cuatro veces, pero, como sus narradores, trata de reconstruir el pasado. Muchas veces los narradores de Juan Rulfo no obtienen una respuesta de sus oyentes, que obviamente prefieren desplazar o reprimir sus recuerdos, pero los lectores pueden afirmar que la obra de Rulfo es eminentemente adaptada a la memoria.

Gabriel García Márquez cuenta en sus Breves Nostalgias sobre Juan Rulfo que "podía recitar el libro completo, al derecho y al revés, sin una falla apreciable, y podía decir en qué página de mi edición se encontraba cada episodio, y no había un solo rasgo del carácter de un personaje que no conociera a fondo" (Fell: 800).

Otro colega, Augusto Roa Bastos, en Los trasterrados de Comala, describe los textos de Rulfo como casas donde el lector puede entrar y habitar, y dice también que tiene "la sensación de no haber salido más de Comala en tierras de la Media Luna, desde la primera vez que bajé ¡cuánto hace! a esta trastierra" (Fell: 802). En otras palabras, la obra de Rulfo se puede comparar con los "teatros de memoria" y a los "palacios del recuerdo" que los oratores de la Antigüedad edificaron en sus mentes para organizar sus experiencias.

$\mathrm{Al}$ igual que Miguel Ángel Asturias, que en Las leyendas de Guatemala describe una "ciudad formada de ciudades enterradas, superpuestas, como los pisos de una casa de altos", donde "la memoria gana la escalera que conduce a los ciudades españolas", precolombinas, etcétera, Rulfo ha construido un pueblo o unas casas literarias, donde la memoria reside. En lo que sigue voy a discutir cómo la arquitectura descrita en esa obra de Rulfo contribuye a la construcción de este palacio -o pueblo- de la memoria.

Arquitectura literaria y edificios de memoria se encuentran entre todos los representantes del realismo mágico -en la obra de Miguel Ángel Asturias, en las ficciones "proustianas" de Alejo Carpentier, en José María Arguedas, en La casa de los espíritus de Isabel Allende, en La mujer habitada de Gioconda Belli-, pero es especialmente interesante observar el parentesco entre Gabriel García Márquez y Juan Rulfo. La biografía El viaje a la semilla de Dasso Saldívar sobre García Márquez (el título es tomado de un cuento "arquitectonico" de Carpentier) abre con la relación del viaje de García Márquez y su madre a Aracataca para vender la casa de los abuelos, un nuevo encuentro que fue "uno de los hechos más decisivos de su vida literaria" (Saldívar 1997: 25). Una experiencia análoga da la llave a Pedro Páramo. En su Autobiografía armada, Rulfo cuenta: 
Fue cuando regresé al pueblo donde vivía, 30 años después, y lo encontré deshabitado. Es un pueblo que he conocido yo, de unos siete mil, ocho mil habitantes. Tenía 150 habitantes, cuando llegué. Las casas aquellas inmensas - es uno de esos pueblos muy grandes, las tiendas ahí se contaban por puertas, eran tiendas de ocho puertas, de diez puertas - y cuando llegué las casas tenían candados. La gente se había ido, así. Pero a alguien se le ocurrió sembrar casuarinas las calles del pueblo. Y a mí me tocó estar allí una noche, y es un pueblo donde sopla mucho el viento, está al pie de la sierra madre. Y en las noches las casuarinas mugen, aullan. Y el viento. Entonces comprendí yo esa soledad de Comala, del lugar ése. (...) Cómo aquella gente dejó morir al pueblo. Cómo se justificaba el querer abandonar aquellas cosas. Su casa, todo (Roffé 1973: 60-2).

La memoria necesita - como ha mostrado Maurice Halbwachs en su crítica de la filosofía de Henri Bergson - un marco social, puntos externos que pueden apoyar a la memoria, y Rulfo ha dicho que "[y]o necesito ubicarme en un ambiente determinado" (Antolín 1991: 15). La casa y el pueblo ofrecen tales marcos sociales de la memoria donde los recuerdos se evocan, pero aún ese marco minimal es inseguro en la obra de Rulfo, pues todos puntos de apoyo tienden a desaparecer y es extremadamente difícil situarse en "un ambiente determinado".

\section{Un pueblo fantasma}

Pedro Páramo es dueño de "toda la tierra que se puede abarcar con la mirada" (183), y ese poder total priva a los habitantes de Comala de todo - aparte del deseo de recobrar su vida por los recuerdos. Es en el nuevo encuentro con la soledad del pueblo fantasma que inspiró a Rulfo en esa novela donde Pedro Páramo pierde su poder total y en una reacción de rencor decide "olvidar" Comala: "Me cruzaré de brazos y Comala se morirá de hambre" (187). La cuestión de la memoria y del olvido es desde la primeras líneas indicado como el tema más importante. Ya en el primer párrafo, Dolores, la madre del Juan que realmente es el hijo despreciado de su padre, dice: "El olvido en que nos tuvo, mi hijo, cóbraselo caro" (179).

Regresar es recordar, y la madre de Juan Preciado pacta con su hijo de vengarse por el olvido que ha destruido su vida. En cierto modo, la novela no solamente cuenta de esa venganza, sino que es la venganza, porque regresando a Comala Juan Preciado evoca todos los recuerdos de ese lugar, la brutalidad de su padre y las atroces reminiscencias en pena en el purgatorio de Comala - donde hace tal calor "que muchos de los que allí se mueren, al llegar al infierno, regresan por su cobija" (182). Simultáneamente, Rulfo expone la represión católica y se aprovecha del concepto del Purgatorio para criticar a Pedro Páramo y a los habitantes de Comala: "Y ésa es la cosa por la que esto está lleno de ánimas; un puro vagabundear de gente que murió sin perdón (...)" (229).

La maldad de Pedro Páramo culmina cuando él, en su rencor por causa de la falta de respeto de los habitantes de Comala hacia su dolor por la muerte de Susana San Juan toma la decisión fatal de "olvidar" Comala. Pero aunque Pedro Páramo practica el "ninguneo" -descrito por Octavio Paz en El laberinto de la soledad - los recuerdos de los habitantes son "untadas a las paredes" de las casas en Comala: "Este pueblo está lleno de ecos. Tal parece que estuvieron encerrados en el hueco de las paredes o debajo de las piedras" (218). Respaldado por la presencia de las ruinas, los habitantes muertos de Comala reaparecen como fantasmas y con sus azotes castigan al cacique duro por el olvido en que tenía a sus mujeres e hijos. 


\section{El gótico mexicano}

El universo de Rulfo es un universo de muertos y fantasmas, de ruinas y caballos errantes, de lunas y murciélagos, de horror y amor loco; en breve: un universo que se asemeja al romanticismo gótico del siglo XVIII. En su libro El lugar de Rulfo, Jorge Ruffinelli - que ha señalado ese parentesco con el romanticismo gótico - no discute la función específica de la arquitectura, pero en el artículo "Museos mentales" sobre el estilo gótico, Emily Jane Cohen ha propuesto que esa arquitectura pertenece a la tradición anciana de teatros de memoria y propone dos explicaciones de la aparición de este universo: primero, la crisis de la autoridad del poder feudal y segundo, la crisis de la autoridad de la religión. La crisis del feudalismo reapareció en México con la Revolución que empezó una década antes del nacimiento de Rulfo en 1918, y la crisis de la Iglesia estalló durante la infancia de Rulfo con la rebelión de los Cristeros 1926-29. Además, el éxodo rural de los años 30 y 40 -descrito por Rulfo en Paso del Norte- dejó los pueblos deshabitados, y eso, naturalmente, debilitó la fuerza de los valores tradicionales. Así, los supuestos para un romanticismo gótico fueron presentados, y en varias maneras se pueden reconocer los muesos mentales descritos por Emily Jane Cohen en la novela y los cuentos de Rulfo.

Al llegar a Comala, Juan Preciado inmediatamente encuentra un pueblo que es un museo de sí mismo: "Miré las casas vacías; las puertas desportilladas, invadidas de yerba" (184). En el romanticismo gótico del siglo XVIII, las ruinas fueron ruinas de palacios y castillos, en el gótico mexicano del siglo XX, las ruinas son ruinas de los campesinos y recogederos laberínticos de los valores de esos campesinos pobres. Juan Preciado pasa por la puerta de una Eduviges Dyada que, como dice él, "tenía todo dispuesto (...) haciendo que la siguiera por una larga serie de cuartos oscuros, al parecer desolados” (185 f). El pasillo angosto está lleno de bultos, y Eduviges Dyada dice: "Tengo la casa toda entichilada. La escogieron para guardar sus muebles los que se fueron, y nadie ha regresado por ellos" (186); y se nota una analogía entre los tiliches o trastos recogidos en este espacio y los recuerdos y pedazos de recuerdos recogidos dentro del discurso temporal de la novela. Más tarde en la novela, los recuerdos se comparan explícitamente con trastes y cosas despedazadas, pero en un contexto donde se destaca que cada pedazo puede conducir a otros pedazos: "Nunca quiso revivir ese recuerdo porque le traía otros, como si rompiera un costal repleto y luego quisiera contener el grano" (244).

Al entrar en el universo de Comala, Juan Preciado pierde el sentido de realidad —al ver a "una señora envuelta en su rebozo que desapareció como si no existiera" (184) — y esa disolución de la realidad concreta es otro aspecto del mundo gótico. Emily Jane Cohen nota que la caída de las autoridades tradicionales fue un reto para los sentidos: si los valores y creencias tradicionales perdían su fuerza, los sentidos obtenían una nueva autoridad. Sin embargo, este nuevo reino de la experiencia sensórica tuvo por efecto un cierto riesgo de sentimientos de nada y nulidad: "Una mente inocupada es en algún modo aniquilada" y "ejercicios repetidos de los sentidos" son el remedio contra la irrealidad, escribió John Locke.

No obstante la multitud de fantasmas góticos en la obra de Rulfo, es obvia la importancia de la experiencia sensorial, y como una respuesta perversa a las reflexiones de Locke, Rulfo ha creado al personaje Macario que tiene "la cabeza tan dura" y que gusta "dar de cabezazos contra lo primero que encuentr[a]": el suelo y las paredes de su cuarto, porque "me 
vivo siempre metido en mi casa" (63). La meta de este "exercisio repetido" de la cabeza y el sentido del tacto es desplazar las condenaciones de la cura y crear una realidad donde tenga autonomía.

\section{La Comala recreada}

La Comala de la memoria se presenta de dos maneras: como utopía y ruina, como unidad y como fragmentos. Pero lo que las dos Comalas tienen en común es una dependencia de la experiencia sensorial - de la vista, del oído, del sabor, del olor, del tacto. La Comala idealizada del recuerdo es "un pueblo que huele a miel derramada" o "a pan recién horneado" (223), rodeada de "una llanura verde" y tan blanca que está "blanqueando la tierra, iluminándola durante la noche" (180). En los recuerdos de desilusión también es posible sintetizar los recuerdos en una impresión sensorial: "Hay pueblos que saben a desdicha" (260); pero en general la utopía de unidad se contrasta con las ruinas de la desilusión. Cuando Juan Preciado entra en una de las casas de Comala, esta es "una casa con la mitad del techo caída. Las tejas en el suelo. El techo en el suelo" (224), y a la entrada, Juan Preciado se comporta como Macario dando "cabezazos" (224) contra la puerta.

Como consecuencia del ritmo, del tono y del "leitmotiv" de la experiencia sensorial, el lector siente una unidad, una estructura muy fuerte en la novela, como equipada con "el sexto sentido" (198) del cual habla Doña Eduviges a Juan Preciado. El texto como tal se presenta como pedazos de la memoria, como fragmentos, como un espacio discontinuo. A pesar de la importancia de la experiencia sensorial es imposible formarse una imagen realista y detallada de Comala. Se mencionan paredes, ventanas, casas, patios, calles, un puente, una iglesia, una plaza, pero como signos abstractos más que como referencias que podrían individualizar el pueblo de Comala. Se puede decir que el espacio de la novela oscila entre estilización e impresión, y por causa de esa recreación ambigua de Comala, el texto resulta un reto para el lector. Como Juan Preciado, el lector entra en un espacio donde cada paso da motivo a reflexiones sobre las preguntas más fundamentales: ¿quién soy?, ¿de dónde vengo y hacia dónde voy?, ¿cuándo y hasta cuándo? Al final, Pedro Páramo "se fue desmorando como si fuera un montón de piedras" (304), pero, al mismo tiempo, el mosaico de la novela se cumple, no como un montón de recuerdos aislados sino como una casa de memoria.

\section{Trazando los límites}

La autonomía supone la capacidad de trazar un límite entre lo mío y lo tuyo. Normalmente, la arquitectura funciona como un instrumento para definir un espacio, para trazar los límites entre dimensiones como adentro y afuera, encima y debajo, centro y margen. De esta manera, la arquitectura -la casa- es un instrumento privilegiado de orientación, pero en el universo rulfiano la falta o la fragilidad de la casa es un indicio de la falta o la fragilidad de una vida personal, autónoma. En la mayoría de los cuentos, los protagonistas no están en su casa o no tienen casa y, como desamparados, pierden la capacidad de orientarse. 
En Nos han dado la tierra, el punto de partida es esa falta de puntos de referencia: “...tantas horas de caminar sin encontrar ni una sombra de árbol, ni una semilla de árbol, ni una raíz de nada" (7), seguida del establecimiento del punto de referencia mínimo: "el ladrar de los perros". Para el narrador, que es miembro de un pequeño grupo de cuatro campesinos que buscan sus tierras, las sin-fronteras del llano motivan una cuestión blasfémica: “¿Quién diablos haría este llano tan grande?" (8); además, para los sentidos, el llano implica un reto demasiado grande: "Se le resbalaban a uno los ojos al no encontrar cosa que los detenga" (9). Desarmados y expuestos al calor del sol y al sinfín del llano, los cuatro campesinos ex-revolucionarios no pueden orientarse. Las categorías de espacio, tiempo y personalidad no sirven de nada en el llano. Parece que la enumeración de solamente cuatro personas es un gran problema para el narrador y la medición de la distancia es insegura: "Y a mí se me ocurre que hemos caminado más de lo que llevamos andado" (8). "Se me ocurre eso", repite el narrador. Además, las numerosas repeticiones y los deícticos como "eso" y "este" suscitan la impresión de que las referencias internas del texto (o plática) sirven como compensación de la falta de referencias externas. En cierto sentido, el texto sirve como una estructura arquitectónica donde se puede distinguir entre este lado y el otro lado, adelante y atrás, debajo y encima.

Hay otros cuentos en los que la falta de una casa tiene consecuencias para la capacidad de estructurar la vida y las experiencias. En No oyes ladrar los perros, el ladrar de los perros, como en Nos han dado la tierra, significa la protección de un pueblo. En el cuento Es que somos muy pobres, la casa del narrador es inundada verticalmente por un aguacero y horizontalmente por un río, y al final en la inundación se incluye la hermana del narrador: "Por su cara corren chorretes de agua sucia como si el río se hubiera metido dentro de ella" (29). En El hombre, la narrativa de fuga y persecución da ocasión a una representación de horizontes perpetuamente móviles: “...detrás de un horizonte estaba otro y el cerro por donde subía no terminaba" (32). En La Cuesta de Comadres, el narrador que vive en esa cuesta en vano ha tratado de reparar las casas dejadas por sus vecinos: "Primero les cuidé sus casas; remendé los techos y les puse ramas a los agujeros de sus paredes; pero viendo que tardaban en regresar, las dejé por la paz" (16). Cuando remienda su propia propiedad, un costal, finaliza en un impulso extraño determinado por la luna de matar a un amigo con la aguja usada para coserle los agujeros. Finalmente, en El día del derrumbe, el punto de partida son los acontecimientos después de un derrumbe donde las casas se "derrumbaban [...] como si estuvieran hechas de melcocha" (140).

En ninguno de esos cuentos es importante la metáfora de arquitectura, pero en Luvi$n a$, que en cierto sentido es un precursor de Pedro Páramo, la arquitectura y el romanticismo gótico dominan el universo de la narrativa.

\section{Un lugar endemoniado}

Normalmente, las ruinas son el resultado de un proceso en el que la historia se convierte en natura, pero en Luvina la natura misma es una ruina: "Está plagado de esa piedra gris con la que hacen la cal, pero en Luvina no hacen cal con ella (...) El aire y el sol se han encargado de desmenuzarla" (102). El cuento de esa "ruina géografica" (Antolín 1991: 18) 
es construido como la narración de un maestro que ya ha vivido y, en cierto sentido, muerto, dirigida a otro viajero (que tal vez es su doble) que está de camino hacia el mismo "lugar endemoniado" (106). Un viento fuerte que se parece a los vientos apocalípticos en las obras de Asturias y García Márquez es el poder dominante y destructor de ese lugar, y es una fuerza que hace ruinas de las casas. En este proceso, la analogía arquitectónica resulta doble: el ser humano se parece a una casa y las casas se parecen a seres humanos - en tanto que el viento es retratado como un monstruo:

\footnotetext{
-Ya mirará usted ese viento que sopla sobre Luvina. Es pardo. Dicen que arrastra arena de volcán; pero lo cierto es que es un aire negro. Ya lo verá usted. Se planta en Luvina prendiéndose de las cosas como si las mordiera. Y sobran días en que se lleva el techo de las casas como si se llevara un sombrero de petate, dejando los paredones lisis, descobijados. Luego rasca como si tuviera uñas: uno lo oye a mañana y tarde, hora tras hora, sin descanso, raspando las paredes, arrancando tecatas de tierra, escarbando con su pala picuda por debajo de las puertas, hasta sentirlo bullir dentro de uno como si se pusiera a remover los goznes de nuestros mismos huesos. Ya lo verá usted (103).
}

Se desprende desde el comienzo del cuento que el narrador no tiene la misma interpretación del lugar que los habitantes: "Dicen los de Luvina que de aquellas barrancas suben los sueños; pero lo único que vi subir fue el viento..." (102). Y: "Dicen los de allí que cuando llena la luna, ven de bulto la figura del viento recorriendo las calles de Luvina, llevando a rastras una cobija negra; pero yo siempre lo que llegué a ver, cuando había luna en Luvina, fue la imagen del desconsuelo...siempre" (105). Así, hay un intercambio entre los habitantes de Luvina y ese viento, que forma parte de su comunidad. Para el narrador, en cambio, el viento es solamente un viento, una fuerza natural o una imagen abstracta. No obstante, esa fuerza objetiva se convierte en una pesadilla subjetiva tan pronto como el narrador, mediante la memoria, resucita sus experiencias de Luvina. Y como los habitantes de Luvina han visto el viento "Ilevando a rastras una cobija negra" el narrador ha visto a los mismos habitantes "pasar como sombras, repegados al muro de las casas, casi arrastrados por el viento" (111).

$\mathrm{La}$ arquitectura sirve como un límite entre el adentro y el afuera, y los habitantes de Luvina enfrentan el poder del viento como si fueran casas. El narrador se compara con una casa cuando dice que el efecto del viento es que uno siente como si este "se pusiera a remover los goznes de nuestros mismos huesos" (103). Y también compara a los habitantes de Luvina con casas diciendo que en Luvina es "como si a toda la gente le hubieran entablado la cara". Con su plática -que más parece la plática de un borracho o un loco- el narrador evidentemente no ha "entablado" su cara, y su experiencia con la iglesia en Luvina representa su incapacidad de protegerse contra las fuerzas externas:

Era un jacalón vacío, sin puertas, nada más con unos socavones abiertos y un techo resquebrajado por donde se colaba el aire como por un cedazo.

El narrador dice que su cuento se funda en sus recuerdos de Luvina, pero así como no puede separar afuera de adentro, no puede separar el pasado del presente. Así, la memoria supone una distancia entre el presente y el pasado, pero para el narrador el pasado es un trauma presente. Dice que "[r]esulta fácil ver las cosas desde aquí, meramente traídas por el recuerdo, donde no tienen parecido", y es claro que no le "cuesta trabajo" al narrador hablar sobre Luvina porque mentalmente nunca ha dejado este "lugar donde anida la tristeza". 
Cuando toma una cerveza inmediatamente piensa en los mezcales de Luvina, y cuando toma otra cerveza explica que "sea nomás para que se me quite el mal sabor del recuerdo".

\section{La ambiguiedad de la memoria}

El laberinto de la soledad, publicado en 1950, en la misma década en que Rulfo publicó su obra, y caracterizado por Rulfo como "uno de nuestros grandes libros" (Antolín 1991: 19), se puede leer como una interpretación del mundo rulfiano: "La historia de México es la del hombre que busca su filiación, su origen" (Paz 1982: 18). El punto de partida de esa búsqueda de los desheredados es la falta de casi todos los puntos de apoyo ("una oscura conciencia de que hemos sido arrancados del Todo" (19) y su culto a la muerte y su "ninguneo" parecen maneras de apoderarse de las fuerzas que les han privado de toda herencia. Temeroso de la mirada ajena, el "mexicano" "se vuelve sombra y fantasma, eco" (38), pero disfrazado como un "Ninguno" se guarda contra lo que le reduce a la Nada. El lenguaje se convierte en un silencio que protege al "Ninguno" (40) contra la dureza y hostilidad de su ambiente: "Atraviesa la vida como desollado; todo puede herirle, palabras y sospecha de palabras. Su lenguaje está lleno de reticencias, de figuras y alusiones, de puntos suspensivos; en su silencio hay repliegues, matices, nubarrones, arco iris súbitos, amenazas indescifrables" (26). Entonces el hermetismo y el laconismo no solamente expresan una falta de recuerdos sino también un deseo de proteger los recuerdos. Paz usa la metáfora arquitectónica del "muro de soledad" (44) y Rulfo usa la misma metáfora cuando describe la desconfianza de la gente en Luvina, que daba la impresión de haber "entablado la cara" (Rulfo: 104).

En cierto modo los recuerdos de sus muertos son la única propiedad de la gente de Luvina y por eso se defienden contra todo cambio: "Pero si nosotros nos vamos, ¿quién se llevará a nuestros muertos?" (110) Octavio Paz sugiere que la fascinación que la muerte ejerce sobre los mexicanos puede ser un efecto de su "hermetismo y la furia con que lo rompe[n]" (Paz: 52). En todo caso, el culto a la muerte es reflejo de una memoria en la que el pasado domina el presente.

Se puede distinguir entre varios aspectos del recuerdo o de la memoria. Con Marcel Proust y Walter Benjamin se pueden distinguir la memoria involuntaria y la memoria voluntaria. En la memoria involuntaria se forma una experiencia épica donde el "memorioso" súbitamente reconoce relaciones escondidas u olvidadas, y donde un atmósfera cinestética se ata a los recuerdos. En contraste con esa memoria involuntaria, la memoria voluntaria, apoyada de varios medios mnemotécnicos, es una memoria controlada, en la que los recuerdos se localizan en espacio y en tiempo como informaciones precisas, pero sin atmósfera. Sin embargo, en la obra de Rulfo, la memoria tiende a ser una fuerza que involuntariamente devora el presente o lo sustituye. No forma una experiencia que puede servir como guía en la vida, sino que forma una obsesión que impide la vida. Los actos como el asesinato en La cuesta de las Comadres bajo la luna gótica se realizan como en un trance. La "vida" de Pedro Páramo es dedicada a la muerte: es "un rencor vivo" (182).

En Pedro Páramo, el padre Rentería dice que "[a] mí se me ha olvidado el sabor de las cosas". El recuerdo tiene un mal sabor en toda la obra de Rulfo. Los personajes son desmemoriados que viven al margen de la historia, en un tiempo donde fracasa la memoria. El 
maestro en Luvina usa cerveza para escaparse de sus recuerdos malos (el mal sabor de sus recuerdos es peor que el mal sabor de la cerveza).

El narrador y Natalia en Talpa sufren remordimientos, y los remordimientos implican que Natalia olvide el presente, es decir, al narrador que fue su amante. La memoria se muestra como rencor o como remordimientos, y esas dos formas de la memoria realmente borran "el muro" entre pasado y presente. Para la sed de venganza, el presente es nada, porque es definido y determinado por el pasado, mientras que para la verguënza el pasado fue tan malo que destruye la posibilidad de vivir en el presente. La expiación, el exorcismo y la repetición coactiva expresan una memoria perversa o negativa, y para algunos de los personajes rulfianos - por ejemplo el padre en ¡Diles que no me maten!, que confía "en el olvido en que lo tenía la gente" (95) - el olvido es la única esperanza.

En el cuento El llano en llamas, los guerrilleros son verdugos y víctimas al mismo tiempo porque sus actos son ecos ajenos de una historia que tiene su centro en otro lugar. El narrador cuenta: "Ésperábamos dejar pasar los años para luego volver al mundo, cuando ya nadie se acordara de nosotros". Como otros de los narradores rulfianos, el narrador de este cuento pretende controlar o conjurar sus malos recuerdos ("Me acuerdo muy bien de todo") pero la diferencia entre el pasado lejano y el pasado próximo se borra, y, como dice Francisco Antolin, el narrador se absorbe por la inmediatez dramática del monólogo interior" (Antolín: 27), se entrega a un interminable soliloquio que reitera su angustia y sus obsesiones.

En cierto sentido, la historia es el enemigo verdadero, y el fatalismo de los narradores se puede considerar como una resistencia a la historia. La refutación de la historia -que se acerca a un concepto del mundo mítico- no puede cambiar la historia, pero puede funcionar como un apoyo mental. Como dice el narrador en Nos han dado la tierra: "Nosotros no hemos dicho nada contra el Centro. Todo es contra el llano... No se puede contra lo que no se puede. Eso es lo que hemos dicho" (10). La indiferencia sirve -como dice William Rowe"para enfrentar la opresión sin tener que abrir las puertas a todo el odio acumulado (contienda que los campesinos inevitablemente perderían), pero evitando la identificación con el agresor o la desviación del odio hacia ellos mismos" (Cuadernos: 244).

\section{Apuntes conclusivos}

La cuestión de memoria fue muy personal para Rulfo, aunque se aprovechaba de la memoria colectiva de la iglesia y del culto popular de la muerte para expresar esa cuestión. Ha dicho que, "[c]uando escribí Pedro Páramo sólo pensé en salir de una gran ansiedad" (Cuadernos: 7). Rulfo tuvo toda la experiencia sangrienta de la Revolución Cristera: matanzas, ahorcados, fusilamientos, orfandad, la vivencia de la crueldad que esos hechos dejaron en su infancia. Obsesiones y traumas son consecuencias casi inevitables de experiencias de ese tipo y parece que el desplazamiento de la vida rural en Jalisco a la vida urbana de la Ciudad de México implicó un resucitamiento de los recuerdos penosos. En Pedro Páramo el éxodo rural se ha trasladado a la década de la Revolución, como se desprende de la descripción intensa: "Recuerdo días en que Comala se llenó de adioses y hasta nos parecía cosa alegre ir a despedir a los que se iban" (258). Para Rulfo la "plática consigo mismo", la lectura y después la escritura fueron los medios para obtener una 
maestría del pasado, de esos recuerdos superpuestos y "telescópicos" que no le dejaran en paz. Recreando Comala, Luvina, La Cuesta de las Comadres y otros lugares cargados de memorias, Rulfo podía evocar sus recuerdos y al mismo tiempo revocar el poder de esos recuerdos sobre su ánimo.

\section{Bibliografía}

Todas las referencias a la obra de Rulfo, véase: Fell (1992).

Antolín, Francisco. 1991. Los espacios en Juan Rulfo. Miami: Ediciones Universal.

Barrere, Bernard. 1987. “La représentation de l'espace dans El llano en llamas. En: Ezquerro (ed.).

Cohen, Emily Jane. 1995. "Museums of the Mind. The Gothic and the Art of Memory". ELH. $62(3)$.

Ezquerro, Milagros (ed.). 1987. Le récit et le monde. H. Quiroga, J. Rulfo, R. Bareiro-Saguier. Paris: Editions L'Harmattan.

Fell, Claude (ed.). 1992. Juan Rulfo. Toda la obra. Edición crítica. Mexico: Consejo Nacional para la Cultura y las Artes.

García Márquez, Gabriel. 1992. “Breves nostalgias sobre Juan Rulfo”. En: Fell (ed.).

Halbwachs, Maurice. 1976. Les cadres sociaux de la mémoire. Paris: Mouton.

Iglesias, Juan Carlos. 1987. “El llano en llamas: una lectura imaginaria”. En: Ezquerro (ed.).

Klahn, Norma. 1992. “La ficción de Juan Rulfo: nuevas formas del decir”. En: Fell (ed.).

Paz, Octavio. 1982. El laberinto de la soledad. México: Fondo de Cultura Económica.

Poniatowska, Elena. 1992. “¡Ay vida, no me mereces!”. En: Fell (ed.).

Roa Bastos, Augusto. 1992. "Los Trasterrados de Comala". En: Fell (ed.).

Roffe, Reina (ed.). 1973. Autobiografía armada. Buenos Aires.

Ros, Arno. 1972. Zur Theorie literarischen Erzählens. Mit einer Interpretation der "cuentos" von Juan Rulfo. Frankfurt am Main.

Rowe, William and Vivian Schelling. 1996. Memory and Modernity. Popular Culture in Latin America. London, New York: Verso. 
Rowe, William. 1985. "La ley, la culpabilidad y la indiferencia en los cuentos de Juan Rulfo". Cuadernos Hispanoamericanos. 421-3.

Ruffinelli, Jorge. 1980. El lugar de Rulfo. Xalapa: Universidad Veracruzana.

Rulfo, Juan. "Pedro Páramo, treinta años después". Cuadernos hispanoamericanos.

Salívar, Dasso. 1997.García Márquez. El viaje a la semilla. La biografía. Madrid: Alfaguara. Yates, Frances A. 1978. The Art of Memory. Harmondsworth: Penguin Books.

Zerlang, Martin. 1988. "Juan Rulfo's Lonely Storytellers". Culture and History. 3. København. 